\title{
Bridging Theory to Practice: Utilizing the Culture- Centered Approach (CCA) to Address Gaps in Community Based Participatory Research (CBPR) Processes
}

\author{
By Sydney Dillard ${ }^{*}$ \\ Agaptus Anaele \\ Rati Kumart \\ Raihan Jamil $^{+}$
}

\begin{abstract}
The purpose of this study is to provide recommendations to bridging the "theoretical" with the "practical" in developing community-based participatory research (CBPR) health communication projects. As illustrated through a review of several case studies from health campaigns using $C B P R$, often times the theoretical orientations of CBPR become secondary to its praxis, with unspoken motives and agendas become motivating factors in guiding the initiatives. These motives may come in the form of funding organization priorities, funded grant proposal constraints, and the desire to continue relationships that are fostered in the development of CBPR projects. In response, this essay reintroduces the culture-centered approach (CCA) as an additional metatheoretical lens that can be utilized in linking theory to practice. The use of specific reflexive exercises are recommended to draw out unseen power differentials within project partnerships, calling into question the fundamental objectives guiding the decision-making processes within CBPR projects. This essay aspires to compel and strengthen CBPR health communication in practice to become more authentic to the orientation's original conceptualization.
\end{abstract}

Keywords: community-based participatory research, culture-centered approach, health communication theory, reflexivity

\section{Introduction}

Strategies to protect and improve the health of communities through education and healthy lifestyles remain a global priority. Threats to public health and safety include smoking, air pollution, HIV/AIDS, substance abuse, and chronic ailments among others and health communication campaigns have become a key strategy to avert the consequences of today's complex health and environmental problems. While health campaigns usually involve the use of mass media and interpersonal channels to encourage healthy and discourage unhealthy behaviors among different populations (Randolph and Viswanath 2004), most campaigns seek to change the behavior of community constituents through persuasive strategies. As a result of these persuasive goals, considerable health campaigns are rooted in social and behavioral theories such as the theory of reasoned action and social cognitive theory, that attempt to predict and control human behaviors (Dutta 2010). Such health campaign models are often

\footnotetext{
*Assistant Professor, DePaul University, USA.

${ }^{\dagger}$ Assistant Professor, Emerson College, USA.

${ }^{\ddagger}$ Assistant Professor, Central Connecticut State University, USA.

${ }^{+}$Assistant Professor, Zayed University, United Arab Emirates.
} 
criticized for centering on individual and cognitive variables while neglecting socio-cultural contexts, which largely shape the spaces in which health behaviors choices are made.

In this article, we examine case studies of health communication campaigns that attempt to move away from individually-focused control of health behaviors through the application of community-based participatory research (CBPR) and uncover its co-optation in practice, by certain cultural approaches. In response, the authors suggest the culture-centered approach (CCA), as a remedy to bring CBPR closer to its seminal conceptualization. First, we examine a brief history of culturally focused health campaigns' through the exploration of cultural sensitivity, cultural competency and CBPR. The literature examined is in no way exhaustive in terms of CBPR health campaigns literature, but rather an attempt to distill of certain qualitative oriented trends that may surface during the application of community-based participatory health campaigns.

In our analysis we examine select cases of such health interventions conducted in a top-down manner, with our overarching goals being (a) to interrogate the conceptualization of cultural approaches to CBPR versus the actual implementation of CBPR projects, (b) to illustrate the overlap between culturecentered approach (CCA) and CBPR, and (c) to offer practical examples on ways CCA can strengthen the practice of CBPR. We consider this an important contribution because of the potential for collaboration among scholars in university-community relationships and partnerships as described by scholars in the field (Dillard, 2014, Dillard et al., 2014), particularly in this era of crossdisciplinary collaboration to solve human problems. First, we map the trajectory of culturally-focused health campaigns which lead to the evolution of the community-based participatory practices and culture-centered approaches to health interventions.

\section{Community-Based Participatory Research (CBPR): An Overview}

Three interrelated and core concepts bind the ideologies of CBPR participation, research, and action (Hall 1992, Minkler 2004, 2005, Minkler and Wallerstein 2003) and the Royal Society of Canada describes CBPR as "systematic investigation with the participation of those affected by an issue for purposes of education and action or affecting social change" (Green et al. 1995). One agenda of CBPR is to break down the barriers between a researcher and his/her researched community members and focuses on distributing equal contributions between the two parties. Community-based participatory research emphasizes "ethical principles such as self-determination, liberty, and equity and reflects an inherent belief in the ability of people to accurately assess their strengths and needs and their right to act upon them" (Minkler 2004: 684). As an umbrella terminology, CBPR encompasses different research approaches such as participatory action research (PAR), collaborative inquiry, action research, and feminist participatory research. It is not best defined as a methodology, but instead as an orientation to research that utilizes any number of quantitative or qualitative methodologies. According to Cornwall and Jewkes 
(1995: 1667), CBPR is not the "methods used but methodological contexts of their application", and is unique in "the attitudes of researchers, which in turn determine how, by and for whom research is conceptualized and conducted [and] the corresponding location of power at every stage of the research process". Another hallmark of this approach is the emphasis CBPR places on individual, organizational, and community empowerment that involve control, participation, and critical awareness (Minkler 2004, 2005, Tapp et al. 2014, McElfish et al. 2017).

Through the process of mutual collaboration and assistance in a CBPR project, the researcher(s) and community participants actively seek to deconstruct power and democratize knowledge so that the academic knowledge of the "outsider" (researcher) and the experiential knowledge of the "insider" (community member) can come together and form a synergistic relationship. Explicit in CBPR processes is the physical and intellectual sharing of all knowledge and resources as pertinent to the common cause/goal of the community and the researcher. The roots of such deconstruction of power and democratization of knowledge come from the necessity to address the colonizing nature of most researchers where the agendas of the dominant status quo are often the primary goals of the research, as opposed to addressing the actual needs of communities at risk (Hall 1992, Minkler and Wallerstein 2003, Minkler 2004, 2005, Kawn and Walsh 2018).

\section{Tensions in CBPR Practice}

Conceptual co-optation of CBPR can often be used through cultural approaches to health campaigns such as cultural competence (CS), demonstrating healthcare professional adeptness at handling multicultural clientele and cultural sensitivity (CS), which offers communication solutions that fit the cultural agenda and health issues considered important by the health communicator (Dutta 2008, Dillard et al. 2014, Dutta et al. 2017). These oversights need to be interrogated for the tensions which they create between CBPR in theory versus CBPR in practice. The most prominent tensions that arise include the insider-outsider tension, inherent power differentials between partners, and the corrosion of trust in these interactions (Dillard et al. 2014, Dutta et al. 2017, Dutta et al. 2013). As these concepts can have a direct and significant effect on the outcomes of CBPR campaign and longevity of trust development, it is pertinent that they are deconstructed in their everyday praxis.

The perceptions of authority, "expert" knowledge, academic background, and financial/ grant standing of a researcher may directly conflict with those of the community members and lead to very real power tensions. Community insiders could easily feel threatened by the power of the outsider to dictate the work (Minkler 2004, 2005, Dillard et al. 2014, Dutta et al. 2017). Insiders could easily find that it is the outsiders who stand to gain the most from any research project in terms of publishing, grant money, salary support, etc. while insiders on the other hand may have to endure and extend waiting periods to receive some basic monetary gains, taking months to reach them (through university or 
other grant institutions). Racial and cultural tensions arise in many CBPR campaigns as such research traditionally deals with disenfranchised communities and are primarily communities of color. Researchers on the other hand in these cases, are rarely of the same race, culture, or ethnicity as the community members; so perceived or real racism is often substantial in these cases (Minkler 2004, Kawn and Walsh 2018).

\section{Cultural Sensitivity in CBPR Practice}

The cultural sensitivity approach to community based participatory projects has in recent times become a favored method for incorporating a more contextualized practice of health interventions. However, the understanding of what being engaged with a community's culture means becomes an exercise in understanding the cultural notions underlying a particular condition and using such knowledge to promote health communication efforts, focusing on the transformation of individual-level health behaviors (Dutta 2007). The cultural sensitivity approach is thus directed toward the goal of producing health interventions that incorporate the cultural characteristics, values, beliefs, experiences, and norms of the target population in the design, delivery, and evaluation phases of the intervention (Resnicow et al. 2002). The call for culturally sensitive health communication is based on the notion that communication about health ought to adapt to the characteristics of a culture in order to be most effective (Dennis and Giangreco 1996, Resnicow et al. 2002, Ulrey and Amason 2001, Kawn and Walsh 2018). Dutta (2008) observes that the essence of a culturally sensitive approach to a CBPR project then become the creation of effective health messages that are responsive to the values and beliefs of the culture.

While this may seem unproblematic at first glance, it strays from the underlying notion of true community participation as outlined in CBPR's theoretical conceptualization. For example, in Friedman and Hoffman-Goetz's (2007) analysis of how to better convey breast cancer information on the Internet to Aboriginal women in Canada, the researchers found that even though there is increased Internet usage among this community, very little of the information on cancer was relevant due to the large number of Aboriginal languages inconsonant with the primarily English information online. Whereas such a studies identify the cultural element of language as a barrier, by outlining the need to be culturally sensitive in health communication efforts, it does not move beyond this juncture to incorporate any form of community building exercise, which utilizes the inherent agency of the community to address this issue from within the local communities. Instead, they transfer these suggestions, or culturally relevant characteristics back to the expert base and use such feedback to further promote the expert agenda of spreading cancer awareness online through means of translation. Such dilemmas of CBPR practice too can be eliminated by emphasizing the role of community partners and peer leaders within local contexts, as suggested by CCA and discussed in detail in latter sections. This in turn affects the potential for sustainability of such health interventions contingent upon community 
involvement and ownership, creating a vicious cycle of reliance purely on the funding agencies supporting such initiatives, and driven by agency agendas.

\section{Cultural Competency in CBPR Practice}

The idea of cultural competence captures the degree of adeptness displayed by healthcare professionals in handling the cultural mores and rituals of other cultures they interact with daily (Campinha 1994). Though there is no consensus on the definition of cultural competence, most share the central theme that health care professionals adjust and recognize their own culture in order to understand the culture of the patients (Betancourt et al. 2005) categorizing a requirement of such competence in organizational, structural, and clinical (interpersonal) settings as entities where health is enacted for ethnic or racial minorities (Betancourt et al. 2016). Other definitions prioritize an understanding of cultural and linguistic needs (Sue and Sue 2012), the ability of health care providers to supersede cultural differences at the patient-provider level (Cooper et. al. 2003). Medical educators have defined eight content areas (general cultural concepts, racism and stereotyping, physician-patient relationships, language, specific cultural content, access issues, socioeconomic status, and gender roles and sexuality) that are taught within a commonly accepted rubric of cross-cultural education curricula (Dolhun et al. 2003).

Betancourt et al. (2005) while establishing a practical framework of cultural competence interventions, include suggestions such as "minority recruitment into the health professions, development of interpreter services and languageappropriate health educational materials, and provider education on cross-cultural issues" as strategies to improve care of disparate ethnicities in the healthcare system. While these strategies serve to address the role of the educator, physician and healthcare provider in the understanding of cultural nuances involved in patient interactions, they assume that the arena for playing out health interventions exists within the biomedical structure. Such an articulation and training of cultural competence sets the expectations, not of a partnership between the patients and their providers, but of a continued dominant position of the professional, eliminating any possibility for dialogue with the patients, to develop an understanding of their cultural contexts. Such an example of health resource marginalization, through a lack of voice is demonstrated in Dutta-Bergman's (2004) dialogues with the Santali communities of Bengal where they state "Where do we have anything babu? Where do Santal's get to say anything?" In contrast CCA aims to provide a space at the table for those that are often the subject of these health interventions, to engage in dialogue with the biomedical professionals, to maximize the effectiveness of such health interventions.

\section{$C C A$ and $C B P R$}

The culture-centered approach (CCA) provides entry points for strengthening CBPR health campaigns by addressing the taken-for-granted assumptions inherent in the ways in which culture is conceptualized. Bringing forth unquestioned 
concepts allows for a deconstructive process that no longer problematizes culture as a barrier to unhealthy behaviors or as a barrier to the success of culturally sensitive persuasive messages, but instead, turns the lens towards the processes by which CBPR health initiatives are developed. In the following sections, CCA draws upon its own scholarly orientation to provide alternative ways of bridging the theoretical with the practical implementation of community-based participatory research while unpacking fundamental understandings of the key concepts: a) community, b) partnerships, and c) trust. Finally, by point out the very gaps in the ways in which health communication is studied in CBPR using the Cultural Sensitivity or Cultural Competency approaches, CCA suggests entry points for filling these voids, thus reinforcing the fundamental tenets that were developed in CBPR's original conceptualization.

\section{Community Defined}

In constructing the basis for developing CBPR health initiatives, researchers must understand and accept particular ways of defining fundamental concepts including the concepts of community, trust, and equitable partnerships. The reason for this assertion is the taken for granted assumptions, surrounding these concepts, which result in them often being glossed over during execution of CBPR in practice. Minkler (2005) deconstructs the notion of "community", bringing forth its underlying definitions in comparison to those which often dominate health communication research by maintaining that CBPR research topics must emerge from the "community". Community is further defined as varying, with no singular definition applicable to all situations (Minkler and Wallerstein 2008). Therefore in first establishing a CBPR agenda albeit originating from within the academy, funding organization, or underserved communities, the notion of community is developed during the establishment of the CBPR partnership.

It is recommended that those brought to the table consider some of the following critical questions: who constitutes the community; who represents the community; who decides who the community partners will be in a CBPR effort, who is defined as being "outside" the community and not invited to participate (p. 53). All of the questions posed are valid and necessary, however little guidance is provided in the practicality of these considerations. For instance, in concluding the defining elements for community selection, Minkler and Wallerstein (2008: 54) note, "... it is important to reflect on whether some groups are being excluded from sitting around the partnership table and to address this issue accordingly". In defining community and the process through which communities come to be constituted, CBPR theoretically engages with the inherent power relations that emerge; through the interactions of resourcerich academics and in resource deprived communities. Some of the most common outcomes of such interactions include the selection of research topics and access to funding sources in supporting health communication projects, as these decisions have historically been made within the academic arena with little to no input from underserved populations (Airhihenbuwa 1995, Dutta 2008, Dutta et al. 2017). 
However, without guidance, steps taken to rupture the centers of power can easily become co-opted as demonstrated through its usage in the cultural sensitivity approach with a focus on the transformation of individual-level health behaviors (Dutta 2007). Thus the definition of "community" can become convoluted with the interests of funding agents or academics as particular groups within disenfranchised communities can and are still removed from the decisions table. The nature by which this inequity is "addressed" largely falls within the hands of academic partners as they develop relationships with particular community entities in the earlier phases of CBPR initiatives.

\section{Research Methods}

The selection of case studies for health communication campaigns utilizing the tenets of CBPR began broadly through a thoroughly review of publications using a keyword search of CBPR, health campaigns, and community and university partnerships. The timeframe for the search parameters were between 2013-2018 using Google scholar. A total of 37 articles fit the search criteria and were then distilled further, in a qualitative content analysis of publications that excluded discussions of power dynamics of university and community partnerships. Thus a total of 5 case studies were selected as instances in which bridging the gap between theory and practice could be most useful.

\section{Case Studies}

Often times the term CBPR can easily become co-opted within the use of community-based research projects that are still situated within the confines of cultural sensitivity or cultural competency research methods that appear to gloss over discussions of power and privilege. These approaches do little to address power dynamics intrinsically situated within the development process of most health communication campaigns, especially those targeting marginalized or underserved populations. Issues under concern have ranged from diabetes awareness, HIV prevention, and obesity more recently (Henderson et al. 2013, Isler et al. 2014, Hamilton et al. 2017). Stakeholders always include at least one academic partner and a locally situated community representative, though coalitions of larger community groups expand to include local physicians, social activists, and other public health representatives from communities under study. 
Table 1. CBPR Case Studies

\begin{tabular}{|c|c|c|c|c|c|}
\hline Case & $\begin{array}{l}\text { Health } \\
\text { Issue }\end{array}$ & Stakeholders & $\begin{array}{l}\text { Target } \\
\text { Population }\end{array}$ & Outcomes & Recommendations \\
\hline $\begin{array}{l}\text { Henderson } \\
\text { et al. } 2013\end{array}$ & $\begin{array}{l}\mathscr{0} \\
\frac{\tilde{\omega}}{\tilde{\sigma}} \\
\vec{\omega}\end{array}$ & $\begin{array}{l}\text {-Community Health Workers } \\
\text {-University of Michigan researchers } \\
\text {-Community Health and Social Services }\end{array}$ & $\begin{array}{l}\text {-African } \\
\text { American } \\
\text {-Latino/a }\end{array}$ & $\begin{array}{l}\text {-iDecide/Decido program } \\
\text {-Animations } \\
\text { - Risk Pictographs } \\
\text {-Issue Card }\end{array}$ & $\begin{array}{l}\text {-More development time for all party } \\
\text { input } \\
\text {-Cultural sensitivity } \\
\text {-Participant comfort } \\
\text {-Changes only after group consensus }\end{array}$ \\
\hline $\begin{array}{l}\text { Isler et al. } \\
2014\end{array}$ & 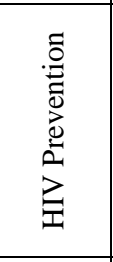 & $\begin{array}{l}\text {-Durham County, North Carolina Black } \\
\text { community } \\
\text {-North Carolina Central University researchers } \\
\text {-Community members } \\
\text {-Social activists } \\
\text {-Public health and human service professionals } \\
\text {-Researchers }\end{array}$ & $\begin{array}{l}\text {-Young black } \\
\text { adults }\end{array}$ & $\begin{array}{l}\text {-HIV Prevention Research } \\
\text { Literacy Curriculum (RLC) }\end{array}$ & $\begin{array}{l}\text {-Team building } \\
\text {-More development time } \\
\text {-Capacity building } \\
\text {-Multiple stakeholder engagement } \\
\text {-Shared decision making }\end{array}$ \\
\hline $\begin{array}{l}\text { Hamilton et } \\
\text { al. } 2017\end{array}$ & $\begin{array}{l}\stackrel{\overparen{v}}{0} \\
0 \\
0\end{array}$ & $\begin{array}{l}\text {-University of Alabama } \\
\text {-Black Belt Community Foundation } \\
\text {-Druid } \\
\text { City Garden Project } \\
\text {-Local primary physician } \\
\text {-Other universities } \\
\text {-Host school }\end{array}$ & $\begin{array}{l}-\mathrm{K}-5^{\text {th }} \text { grade } \\
\text { children } \\
\text {-Local area adults }\end{array}$ & -Health fair & $\begin{array}{l}\text {-Adhere to CBPR principles } \\
\text {-Greater variety of publicity resources } \\
\text {-Effectively create and sustain } \\
\text { relationships between a community and } \\
\text { academia }\end{array}$ \\
\hline $\begin{array}{l}\text { Katigbak et } \\
\text { al. } 2016\end{array}$ & 岕. & $\begin{array}{l}\text { Asian American Partnerships in Research and } \\
\text { Empowerment } \\
\text { Community Health Workers } \\
\text { Community-Based Organizations }\end{array}$ & $\begin{array}{l}\text { Fillipino- } \\
\text { Americans with } \\
\text { Hypertension }\end{array}$ & $\begin{array}{l}\text { Improved participation of } \\
\text { Asian Immigrants in research }\end{array}$ & $\begin{array}{l}\text { Building Trust is crucial in CBPR } \\
\text { CBPR-grounded projects is needed in } \\
\text { clinical research projects in Asian } \\
\text { Immigrant communities }\end{array}$ \\
\hline $\begin{array}{l}\text { Willis et al. } \\
2016\end{array}$ & 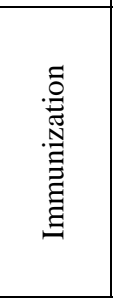 & $\begin{array}{l}\text { Medical College of Wisconsin } \\
\text {-Children's Community Health Plan } \\
\text {-Next Door Foundation } \\
\text {-Neighborhood House of Milwaukee } \\
\text {-Milwaukee Health Department } \\
\text {-State of Wisconsin Department of Health } \\
\text { Services Immunization Program } \\
\text {-Milwaukee County WIC Program }\end{array}$ & $\begin{array}{l}\text { Children under } 14 \\
\text { years of age }\end{array}$ & $\begin{array}{l}\text { Culturally tailored } \\
\text { interventions to reduce } \\
\text { immunization disparities can } \\
\text { be successful using CBPR }\end{array}$ & $\begin{array}{l}\text { CBPR grounded messages may be } \\
\text { effective in increasing immunization } \\
\text { awareness. } \\
\text { CBPR grounded campaigns are } \\
\text { invaluable in the elimination of } \\
\text { immunization disparities and raising } \\
\text { immunization rates to the Healthier } \\
\text { People } 2020 \text { goals }\end{array}$ \\
\hline
\end{tabular}


The most important foci however, is the definition of campaign successfulness as supported through study outcomes and recommendations for executing future CBPR health campaigns. Such outcomes highlight more tangible results from shared decision making within CBPR partnerships including usercentered health information technology programs (Henderson et al. 2013), HIV Prevention Research Literacy Curriculum - RLC (Isler et al. 2014), health fair exhibitions (Hamilton et al. 2017), increased community participation (Katigbak et al. 2016), and culturally-tailored interventions (Willis et al. 2016) all of which provide surface level reviews of the intersections of culture, power, and positionality as these concepts are particularly difficult to overcome without acknowledgement of their existence in academic work.

Along with celebrated outcomes, CBPR cases under review direct future studies to additional recommendation for consideration. Suggestions include the development of longer work timelines for multiple stakeholder engagement and shared decision-making, the use of more culturally sensitive approaches, prioritizing participant comfort, and building trust to effectively create and sustain relationships between a community and academic partners (Table 1). While these tactics and reflections undoubtably assist in the application of CBPR principles, limitations still impede upon scholar's ability to differentiate between culturally sensitive community situated campaigns and truly community-based participatory research health communication campaigns. In the absence of discussion of one's own power, privilege, and positionality, CBPR is more easily employed only using surface level processes that do not engage with the intrinsic power dynamics that are commonly built within community and academic partnerships.

\section{Bridging Theory to Practice Through Lived CCA Experiences: Author Backgrounds}

The authors of this manuscript are presently Assistant Professors in the Communication, Advertising, Marketing Communication, and Business departments of different universities within the US and Middle East. Their research interests include social change, community engagement, culture-centered approach, and health communication. Their approach to research is qualitative, using CCA, which shares similar philosophical assumptions with CBPR to solve human problems. Their interest in CBPR-grounded work began at a major research university, where they took a required qualitative research methods course as graduate students, and subsequently carried out multiple field research projects. The authors collaborated on a $\$ 1.5$ million health project in two minority counties in the US. The project was a partnership among a research university, two local minority coalitions, and underserved communities. Funded by the Agency for Healthcare Research and Quality, the project simplified and disseminated heart health information in the communities.

Our core research question was how can Comparative Effectiveness Research Summary Guides (CERSGs) be utilized in a meaningful way for engaging in dialogue between clinicians and patients within Lake and Marion county, Indiana. Partnerships included researchers from Purdue University, project coordinators, 
community health coalition members, and local community member. The results included a plethora of outcomes including baseline, pre, and post survey measurements, online modules, radio spots, physician videos, press releases, vehicle wraps, and more. The most impactful outcome was the partnership that was developed between the primary community partner and one of the academic research team members that is still intact eight years following the study's completion. Drawing upon these experiences, we now present a review of two CBPR projects that centralized CCA and its impact on campaign implementation for: a) $C U A H D$ and b) CHEP project. These lived experiences speak to the power inequities inherently built into most CBPR campaigns, providing context, and support for drawing out these differentials, thus providing recommendations for such future studies.

\section{CUAHD}

The CUAHD project began with an open townhall meeting that resulted in the constitution of community representatives, joint message tailoring workshops for the design and implementation of the campaign. Drawing upon our collective experience on the project, we engage with tensions about power and political economic interest. Political economy embodies the umbilical relationship between materiality and discourse (Marx and Engels 1976). In this instance, our political economic interest is desire to publish in peer reviewed journals. Publication in peer review journal is considered a measure of success in academe while unfortunately placing pressure on researchers engaged in CBPR projects to find ways to get published from such projects. Sometimes desires to publish obstruct objectives based on community needs. At other times the power differential between the communities and academic partners present tensions. Below is one instance in which the authors have experienced this.

\section{Context and purpose}

A large aspect of the $\$ 1.5$ million grant was to develop trust and cyclical reviews of invested parties in the partnership. The grant budgeted a specific amount for the cost of a community organizer to serve as a liaison both counties and the academy. Shortly after the launch of the townhall meetings, performance evaluations came into question as both community members and research team members began to think through roles and expectations. Community partners of one county regularly noted discontent with having a community organizer represent their county, when the selected personnel lived almost 2 hours away and rarely visited their community. Simultaneously, concerns for reaching performance markers became an issue of concern for the research team as the workload for one community organizer was particularly overwhelming for one person to handle two separate counties. From a political economic standpoint, this lead to apprehension from the research team in reaching goals of data collection and ultimately publishing the results of the study. Through back and forth communication among the partners, the final decision required the replacement of the community organizer twice, the splitting of one job into 
two positions, budget reallocations for the additional position, and community input in the selection of candidates for the two positions.

\section{Challenge}

The decision to find and change community organizers twice during the project was quite challenging. Such a decision posed threats to expectations, study workplans, academic publishing opportunities, and overall trust development between university and community partners. There were multiple instances in which conflicts were met with confusion and apprehension within the academic research team. One of the author's discuss these tensions through reflexive journal exercises that require honest consideration of positionality. This becomes increasingly more difficult as questions of power surface and require engagement daily. In one of the journal entries I wrote:

I've also been hesitant to post because I did not want to blatantly show my disappointment with the community organizer's performance. I find myself conflicted, thinking that this blog post should only be about the CCA process, with little input about my emotional responses to how the process is going. I also worry that certain people will read my posts and be offended, thus causing further dissonance among the academic-community organization group. I really am not sure how to be reflective without showing emotions or even if that is the point of our reflective exercises. I don't know, whenever I think of academic speech or writing, I think the removal of subjective stances. Where are reflective journals positioned with respect to a personal diary vs. an academic reflection? That's a hard mentality to break/modify.

Eventually, the decision to re-envision the role of community organizer came as a collective choice from both community coalition members and academics partners. The final choice led to the development of two separate community organizer positions that allowed for better community representation. This also partially led to the downgrading of the technical members of the project and the reallocation of grant funds. Further, it also diminished the political economic interest of the academic partners to publish about the success or failure of the community-university relationship in the heart disease campaign. In conventional projects, such reversal in decision making will be difficult because it challenges the power structure. The decision of the academic partner is considered sacrosanct. However, through constant reflection, the team agreed it was in the best interest of the community. This held true, even though the final choice to approve these changes, came from the grant's PI. The power differential did not change the Pis positionality, however it was through reflexive journals that all stakeholders were privy to, that these contentions were able to be considered. There were also similar instances of such tensions in individual projects completed by the authors. Below is an additional example from the Adolescent Youth Heart project referenced as (CHIP). 


\section{CHIP Project}

The Adolescent youth heart project emerged from the larger \$1.5 million grant. The CHIP project presented similar goals as CUAHD; it was a collaboration with a minority agency, a high school, and a research university. While the focus of the 1.5million grant was Black adults, the CHIP focused on Black youth. Two of the authors served as a representative of the university in the partnership. One of the authors at the time was a doctoral candidate at the university, and his dissertation depended on the execution of the CHIP project. His political economic interest is evident. In one of my journal entries, I write:

This was a very productive day in terms of attendance and participation. I conducted 8 interviews starting from 9:30 a.m. when I arrived the school to 5:00 p.m., when I departed. The attendance at the workshop was also impressive. We started off with 7 peer leaders, and later on 4 joined, including two old members and two new ones. Both new members were males. I hope we can have more members, because if we do not have members who drive the project that means I will not have data for my dissertation, because my dissertation is tied to this campaign. But this reasoning is selfish and in-authentic to culture centered philosophy. Whether the project works as anticipated or not, I still have data, what matters most is how the youth participate and take ownership of the process.

Here I ponder about the fate of my dissertation should the youth fail to participate in the project. Through this entry, I center my political economic interest in the project. I reflect upon the fate of my dissertation, which is intrinsically tied to the successful execution of the youth campaign. My note here corroborates Davis (2000), Dutta (2008), and Conquergood (1989) that reflexivity allows the researcher to take a critical stance on his/her political economic interest and make such transparent in the research process. While I was interested in the project of engaging black teenagers in addressing heart disease, a part of me was curious about my dissertation which serves my political economic interest of collecting data that will enable me to complete my dissertation and progress to the position of a professor. Through selfreflection, I constantly navigated through this tension of my economic interest versus the philosophy of CCA over the life course of the project.

\section{Power}

Tension about power was also visible in the Youth project. The dialogue in this instance is about evaluation parameters initiated by the researcher. Dialogue is consistent with culture centered philosophy and represent authentic engagement of the youth. However, the proposal of 3-part survey as the yardstick for measuring impact presents tension, because survey is incongruous with culture centeredness. Culture centered approach critiques survey instruments because it reifies researcher object relationship that characterize dominant projects. In her epochal essay, Toward the Development of Critical Health Communication Praxis, Lupton (1994) state that the use of quantitative measures by dominant approaches lead to 
the design and implementation of interventions that lack community voices. Echoing Lupton's argument Airhihenbuwa $(1995,2007)$ argue that the dominant approach to health communication has resulted in the implementation of HIV programs that are incongruent with cultural and contextual realities. Similarly, Dutta $(2008,2007)$ write that by promoting survey instruments that measure individual outcomes, dominant projects create apparatus that blames individuals for failing to adopt "expert" recommended behaviors. According to Dutta (2008, 2007) such individually focused methodology ignores socio-economic, structural, and political factors that compel individuals to make certain choices. Further, CCA challenges the privileging of a way of knowing on the grounds that it promotes the dissemination of Western knowledge as the only way of knowing (Dutta 2008). Against this background, conversations about 3-part survey design in many ways present continuous tension especially for me in the project of engaging the youth. In one of my journal entries I write:

It is sometimes daunting to implement a CCA project because of the temptation to fall into dominant mode. Today was particularly daunting because of our conversation on how to evaluate the project. How does a CCA scholar engage with cultural members about the research component without imposing his/her ideas? How does one negotiate his/her power as the academic partner without further marginalizing the community members? How do you discuss evaluation, survey instruments with cultural members without teaching, education them about the importance of surveys? Did I marginalize my co-participants today? Did I violate CCA principles by telling them how many surveys we shall conduct and why? Is there another way I could have engaged them in the conversation? But I could not converse about survey without telling them about the importance of surveys but telling them about the importance of survey seem top down. How did we even conceive of survey as evaluation parameter in the project? So what is the way out? I guess this is a question I will continue to negotiate throughout this project.

Here we witness a methodological tension between CCA, which locates decision making in the hands of cultural members and dominant approach that controls and predicts the behaviors of communities using surveys. Conspicuous in my reflection is self-interrogation of the rationale of survey as evaluation parameter in a culture centered project. In my journal, I ask, how do you talk about evaluation with community in a non-condescending manner? Who decides what counts as measurement instrument? Does engaging cultural members in the construction of the instrument obliterate the implicit dominant underpinning associated with surveys? These were thoughts that ran through my mind. Drawing upon my commitment to culture centered methodology, I rely on reflexive journal entries to hold myself accountable to my positionality. Through this constant reflection, I become conscious of my method and the inherent weakness.

\section{Results and Recommendations}

Addressing the issue of power inequities can fall within a spectrum of practical responses, ranging from halting the entire project until potential community partners express interest, to the selection (or exclusion) of community 
partners whose agendas are congruent with those which ultimately further academic endeavors; such as a focus on scholarly publishing and the necessities for a successful tenure process. These veiled dispositions not only require open dialogue and consideration of their impacts on the CBPR community selection, but also require a bridge between the theoretical to the practical. In response, the culture-centered approach places great emphasis on reflexive processes as an additional mechanism through which privilege and power can be brought to the forefront to strengthen CBPR efforts at true partnerships with the communities involved.

\section{Values of Reflexivity}

What is often omitted from discussions of health communication research is the status through which health communicators and campaign planners find themselves privileged. The position in itself is constituted within its title as well as his/her access to mainstream communicative platforms and discursive spaces of knowledge. In other words, not only do health communicators have access to spaces of knowledge through their academic affiliations, but also fraught within the possession of formal titles such as "healthcare professionals" or "health communicators", we find ourselves unquestionably labeled as experts of knowledge or the gatekeepers to such knowledge structures. The logics motivating agendas of these experts subsequently become unquestioned when taking into consideration the selection of "community" members brought to the table as well as those excluded.

Nonetheless, while receiving the privileges afforded to health expertise, one can never be removed from within the structures that constitute the health expert's position. Within this role are other expectations for furthering one's career as well as strengthening one's place as the coveted health expert. Health communication scholars must answer to funding agencies through quarterly, annual, and final reports, detailing their productivity throughout grant cycles while also engaging with academic structures set within their own culture of tenure and promotion; all of which are agendas that are not overtly seen at the development level of CBPR work. Consequently, it is critical for CBPR health researchers and healthcare practitioners to constantly re-evaluate their own privilege and the uses of that privilege as an ongoing iterative process that begins well before the initiation of the CBPR process.

The culture-centered approach brings forth this process through the use of reflexive exercises. Dutta (2008: 261) further explains:

A culture-centered research method, therefore, begins by being continuously reflexive about the viability of health problems and solutions as conceptualized within the dominant paradigm. It interrogates the underlying ideologies connected with the very conceptualization of problems and the configurations of solutions proposed by the health communicators... The proposed solution itself needs to be questioned, and in doing this, the researcher needs to bring under scrutiny his or her own biases and the assumptions that drive the type of work that he or she does, and the solutions that he or she is funded to investigate and disseminate. 
Here, the need for reflexive processes developed throughout CBPR implementation requires critical reflection on the part of the researcher. The use of reflexive processes not only excavates obscure ways of creating and sustaining positions of marginality defined by reestablishing researchers as experts for instance in defining community, but also provides a lens for greater transparency and humility on the part of CBPR researchers. Namely, reflexive exercises constantly draw attention to the objectives or goals that motivate each decision point, creating awareness of the structures that support health communication initiatives and simultaneously constrain them. Accordingly, additional motivating forces are brought to light for greater scrutiny by not only the researcher, but also in the selection of the community. With this understanding, greater transparency is linked to a stronger dedication to identifying CBPR goals which all involved parties are privy to, thus contesting the sacredness of knowledge and the locus of decision making.

\section{Reflexivity in Practice}

Reflexive exercises may take on numerous forms throughout CBPR efforts. More tangible procedures may include, for instance, journaling in which reflections are publicly available by all partners, including those from within communities, academics, and funding agency. In doing so all parties have a space for voicing their concerns, in the event of absence from the table in which decisions are made. Thus community members may respond and reflect on their own placement within the process, as well as those more privileged in nature. Such dialogic spaces reflect motives and facilitate further consideration and scrutiny to whether the health initiative objectives are being furthered in the most substantial way possible. The proverbial usage of creating dialogue in which power dynamics are addressed, as ambiguously noted in CBPRs theoretical framework, then becomes a point of interrogation in which all privilege is fundamentally examined in comparison to overarching goals of the partnership.

\section{Reflexive Partnerships in Practice}

CBPR posits the development of collaborative equitable partnerships as a core value in erasing real inequities among partners, though some inequities are difficult to completely remove. With the development of shared control of the decision-making process, CBPR attempts to address partnership inequities through the acknowledgment and discussion of these inequities between partners. Candid conversations should therefore reduce the "impact that power imbalances may have on the relationships among group members and the work of the partnership" (Minkler and Wallerstein 2008: 55). The basic assumption here is that through the opening of dialogue and the development of trust among partners at the table, power inequities at every level of interaction can be minimized through shared influence and equitable control. As noted earlier, markers of marginalization come at varying levels and cannot be dichotomized merely between researcher and community or physicians and patients, for within every culture and structure, 
systems of power continue to exist and function as such. Within the academy, for instance, research assistants often find themselves subordinate to principle investigators of CBPR projects while particular sectors of communities may find themselves marginalized when compared to community leaders and directors of community organizations. These continuing distributions of power mark out the disenfranchised by virtue of positionality. Again, though CBPR supports the development of equitable partnerships in theory, mechanisms for praxis of these orientations can become a challenge in everyday application. Returning to the value of reflexivity, the culture-centered approach can be used to bridge the theoretical origins of CBPR to its implementation by creating a space in which dialogue can be openly collected and free flowing.

As CBPR calls for equitable partnerships, a defining difference between the orientation of CBPR and CCA can be found within their fundamental understandings of "partnership". In relation to the power differences inherent in the structures that shape and are conversely shaped by culture, CCA does not assume that power inequities are minimized or erased through the establishment of open dialogue between partners. Dutta (2008: 262) expands on this fundamental difference:

Being a culture-centered researcher embodies the realization that there is really no way out of this predicament that the very privilege embodied in the position of the researcher is a marker of marginalizing practices of the dominant paradigm .... A culture-centered researcher can't write off his/her privilege by going through a standard set of rituals, but rather must be deeply aware of the ways in which his/her practices continue to embody the privilege, and create discursive closure.

Therefore under the orientation of CCA, equitable partnerships can never truly be achieved unless the entire structure that constitutes one's own positionality is completely removed or reestablished. In that the objectives of CBPR are predominantly focused on sustainable change in community settings through community participation, there is little room for leveling the power structures in place that separate the marginalized from the privileged. Thus, in striving for equitable partnerships, CCA is in contention with CBPR and recommends instead of attempting to minimize or remove power inequities within partnerships, these differences need to be continuously engaged with through the iterative process of reflexivity. In essence, CBPR researchers can strengthen their partnerships by continuously placing their privileges under scrutiny and problematizing the motives for decision-making. This draws attention to not only their motives, but creates a space through which these motives may be engaged with by those most marginalized, thus bringing the research back in comparison to the objective set forth at the inception of the project.

\section{Trust and Reflexivity}

The final concept that has emerged throughout this paper has been the idea trust, developed between partnerships of CBPR projects. Demonstrable through our examination of defining "community" and developing partnerships, essential 
to all these decisions is an element of trust between partners. Though not exclusively stated as such, CBPR recommends fostering solidarity among all participants. Fundamentally, the call for solidarity begins with a unitary approach that develops out of trust. Regretfully, this poses major challenges particularly within partnerships between communities and academics. Developing trust requires lots of time including, "for meetings, for accountability processes, for working through the inevitable conflicts ..." (Minkler and Wallerstein 2008: 110). On the one hand, it often places community members in positions in which they have traditionally been victims of a dominating structure, rather than in participation. Minkler and Wallerstein (2008: 110) maintain that "it asks community members to participate in ways they are not interested in or do not have the time for". On the other hand, the development of trust within CBPR practice still glosses over the very real power inequities that still place researchers in positions of power, irrespective of the candid dialogue developed between community and academic partners.

Returning to its overarching theme of reflexivity, CCA attempts to combat the tendency of tokenism by pushing those within positions of power to truly engage with privilege through an evaluative framework for heath communication application. Trust and solidarity can only be built once one's true ambitions are examined. Note these objectives are in constant interaction with culture and structure, hence the need for reflexivity as an iterative exercise. While developing trust, all partners need to layout their own agendas as transparency again leads to clarity in answering the "how" and "why" of choices made. Additionally, this heightened awareness of expectations can further strengthen humility in decisions determined by the ethics, morals, and values that largely shape the trajectory of CBPR health communication. There is therefore a shift in the exchange of communication between the researcher and community members; one in which a strong bond of solidarity has been developed through honest reflection of all involved.

\section{Conclusion}

The purpose of this manuscript is to bridge the theoretical with the practical in developing CBPR health communication projects. As illustrated in the review of literature, often times the theoretical orientations of CBPR become secondary to its praxis, as unspoken motives and agendas become motivating factors in guiding the initiatives. These practices were noted through the use of more commonly used approaches including cultural sensitivity and cultural competency, directed under the scholarship of CBPR. In response, this essay reintroduces the culture-centered approach as another metatheoretical lens that can be utilized in linking theory to practice. As noted throughout, the use of reflexive exercises can draw out unseen power differences, calling into question the fundamental objectives driving decisions within CBPR projects. In addition to creating discursive space for listening and developing equitable partnerships, CCA recommends utilizing reflexivity to generate a heighten and much deeper awareness of one's own 
privilege. This self-engagement allows for greater care in the ethical and moral decisions set at the heart of power inequities between partnerships. Reflexivity also creates spaces for engaging with these power differentials and allows for new understandings of their meanings and influence in CBPR in practice. It is crucial that these communicative platforms for dialogue be situated within the culture and structure shaping health communicators efforts.

\section{References}

Airhihenbuwa CO (1995) Health and Culture: Beyond the Western Paradigm. Thousand Oaks, CA: Sage.

Airhihenbuwa CO (2007) 2007 SOPHE Presidential Address: On Being Comfortable with Being Uncomfortable: Centering an Africanist Vision in Our Gateway to Global Health. Health Education \& Behavior 34(1): 31-42.

Betancourt JR, Green AR, Carrillo JE, Park ER (2005) Cultural competence and health care disparities: key perspectives and trends. Health Affairs 24(2): 499-505.

Betancourt JR, Green AR, Carrillo JE, Owusu Ananeh-Firempong II (2016) Defining cultural competence: a practical framework for addressing racial/ethnic disparities in health and health care. Public Health Reports 118: 293-302.

Campinha B (1994) Cultural competence in psychiatric mental health nursing: a conceptual model. Nursing Clinics of North America 29: 1-8.

Conquergood D (1989) Establishing the world: Hmong shamans. CURA Reporter 19: 5-9.

Coope LA, Roter DL, Johnson RL, Ford DE, Steinwachs DM, Powe NR (2003) Patientcentered communication, ratings of care, and concordance of patient and physician race. Annals of Internal Medicine 139(11): 907-915.

Cornwall A, Jewkes R (1995) What is participatory research? Social Science \& Medicine 41(12): 1667-1676.

Davis JM (2000) Disability studies as ethnographic research and text: research strategies and roles for promoting social change? Disability \& Society 15(2): 191-206.

Dennis RE, Giangreco MF (1996) Creating conversation: reflections of cultural sensitivity in family interviewing. Exceptional Children 63: 103-116.

Dillard SJ (2014) University-community relationships and partnerships, Encyclopedia of Health Communication.

Dillard SJ, Dutta M, Sun W (2014) Culture-centered engagement with delivery of health services: Co-constructing meanings of health in the Tzu Chi Foundation (慈濟) through Buddhist philosophy. Health Communication 29(2): 147-156.

Dolhun EP, Munoz C, Grumbach K (2003) Cross-cultural education in US medical schools: development of an assessment tool. Academic Medicine 78(6): 615-622.

Dutta-Bergman MJ (2004) The unheard voices of Santalis: Communicating about health from the margins of India. Communication Theory 14(3): 237-263.

Dutta MJ (2008) Communicating health: A culture-centered approach. Malden, MA: Polity.

Dutta MJ (2007) Communicating about Culture and Health: Theorizing Culture-Centered and Cultural Sensitivity Approaches. Communication Theory 17(3): 304-328.

Dutta MJ (2010) The critical cultural turn in health communication: Reflexivity, solidarity, and praxis. Health Communication 25(6-7): 534-539.

Dutta MJ, Anaele A, Jones C (2013) Voices of hunger: Addressing health disparities through the culture-centered approach. Journal of Communication 63(1): 159-180. 
Dutta MJ, Sastry S, Dillard S, Kumar R, Anaele A, Collins W, Roberson C, et al. (2017). Narratives of Stress in Health Meanings of African Americans in Lake County, Indiana. Health Communication 32(10): 1241-1251.

Friedman DB, Hoffman-Goetz L (2007) An exploratory study of older adults' comprehension of printed cancer information: Is readability a key factor? Journal of Health Communication 12(5): 423- 437.

Green LW, George MA, Daniel M, Frankish CJ, Herbert CJ, Bowie WR, O'Neill M (1995) Study of participatory research in health promotion. Review and recommendations for development of participatory research in health promotion in Canada. Ottawa, Ontario: The Royal Society of Canada.

Hall BL (1992) From margins to center? The development and purpose of participatory research. The American Sociologist 23(4): 15-28.

Hamilton KC, Henderson Mitchell RJ, Workman R, Peoples EA, Higginbotham JC (2017) Using a Community-based Participatory Research Approach to Implement a Health Fair for Children. Journal of Health Communication 22(4): 319-326.

Henderson VA, Barr KL, An LC, Guajardo C, Newhouse W, Mase R, Heisler M (2013) Community-based participatory research and user-centered design in a diabetes medication information and decision tool. Progress in Community Health Partnerships: Research, Education, and Action 7(2): 171.

Isler MR, Brown AL, Eley N, Mathews A, Batten K, Rogers R, MacQueen KM (2014) Curriculum development to increase minority research literacy for HIV prevention research: a CBPR approach. Progress in Community Health Partnerships: Research, Education, and Action 8(4): 511.

Katigbak C, Fole M, Robert L, Hutchinson KM (2016) Experiences and lessons learned in using community-based participatory research to recruit Asian American immigrant research participants. Journal of Nursing Scholarship 48(2): 210-218.

Kawn C, Walsh CA (2018) Ethical issues in conducting community-based participatory research: a narrative review of the literature. The Qualitative Report 23(2): 369-386.

Lupton D (1994) Toward the development of critical health communication praxis. Health Communication 6(1): 55-67.

Marx K, Engels F (1976) Marx \& Engels Collected Works Vol 06: Marx and Engels: 1845-1848. Lawrence \& Wishart.

McElfish PA, Narcisse MR, Long CR, Ayers BL, Hawley NL, Aitaoto N, Schulz TK (2017) Leveraging community-based participatory research capacity to recruit Pacific Islanders into a genetics study. Journal of Community Genetics 8(4): 283-291.

Minkler M, Wallerstein N (2008) Community-based participatory research for health: From process to outcomes. San Francisco, CA: Jossey-Bass.

Minkler M (2004) Ethical challenges for the "outside" researcher in community-based participatory research. Health Education \& Behavior 31(6): 684-697.

Minkler M, Wallerstein N (2003) Introduction to community based participatory research. Community-Based Participatory Research for Health: 3-26.

Minkler M (2005) Community-based research partnerships: Challenges and opportunities. Journal of Urban Health 82(2): ii3-ii12.

Randolph W, Viswanath K (2004) Lessons learned from Public Health Mass Media Campaigns: Marketing Health in a crowded media world. Annual Review of Public Health 25: 419-437.

Resnicow K, Braithwaite RL, Dilorio C, Glanz K (2002) Applying theory to culturally diverse and unique populations. In K Glanz, BK Rimer, FM Louis (Eds.), Health Behavior and Health Education: Theory Research and Practice (3rd edn.), pp: 485509. San Francisco, CA, Jossey-Bass. 
Sue DW, Sue D (2012) Counseling the Culturally Diverse: Theory and Practice. John Wiley \& Sons.

Tapp H, Kuhn L, Alkhazraji T, Steuerwald M, Ludden T, Wilson S, Dulin MF (2014) Adapting community based participatory research (CBPR) methods to the implementation of an asthma shared decision making intervention in ambulatory practices. Journal of Asthma 51(4): 380-390.

Ulrey KL, Amason P (2001) Intercultural communication between patients and healthcare providers: an exploration of inter-cultural communication effectiveness, cultural sensitivity, stress and anxiety. Health Communication 13: 449-463.

Willis E, Sabnis S, Hamilton C, Xiong F, Coleman K, Dellinger M, Nugent M (2016) Improving Immunization Rates Through Community-Based Participatory Research: Community Health Improvement for Milwaukee's Children Program. Progress in Community Health Partnerships: Research, Education, and Action 10(1): 19. 